\title{
THE ISOLATION OF ERYSIMOSIDE FROM THE SEEDS OF ERYSIMUM CANESCENS
}

M. T. 'Turakhozhaev, M. -R. I. Shamsutdinov, and T. T. Shakirov

Khimiya Prirodnykh Soedinenii, Vol. 6, No. 1, pp. 139-140, 1970

UDC $615.45: 615.711 .5$

The cardiac glycoside erysimoside, which has been approved for use in medicine [1], was previously obtained from the seeds of Erysimum canescens (hoary erysimum) [2]. A method for its preparation with a yield of about 1.0\% (of the weight of the raw material) has been proposed [3].

We have developed a new industrial method for obtaining erysimoside with a yield of $1.5 \%$ (of the weight of the raw material). The comminuted seeds were defatted with gasoline and dried. The glycosides were extracted with $95 \%$ ethanol by steeping. The extract was concentrated in vacuum $(700-720 \mathrm{~mm} \mathrm{Hg})$ at a temperature not exceeding $45^{\circ} \mathrm{C}$, and acetone was added to precipitate the sugar substances. Then the extract was separated from the sugars that had deposited and was concentrated and treated with ether to eliminate the residues of fatty oils and resinuous substances.

The viscous mass of combined glycosides insoluble in ether was dissolved in water. To purify it from accompanying substances, the aqueous solution was washed with chloroform and passed through a column filled with a mixture of EDE-10-P anion-exchanger (in the $\mathrm{OH}$ form) and $\mathrm{KU}-2$ cation-exchanger (in the $\mathrm{H}-$ form). The erysimoside was extracted from the purified aqueous solution with a mixture of chloroform and isopropanol (1: 1). The chloroformic-ethanolic solution was concentrated until a precipitate appeared and was left for crystallization. The crystals that deposited were filtered off with suction and recrystallized from ethanol. The erysimoside so obtained satisfied the technical requirements.

\section{R E F E R N C ES}

1. V. A. Maslennikova, A. D. Turova, and N. K. Abubakirov, USSR patent no. 186636; Byull. izobr., no. 19, 1966.

2. V. A. Maslennikova, F. S. Khristulas, and N. K. Abubakirov, DAN SSSR, 124, 822, 1959; ZhOKh, 31, $2069,1961$.

3. V. A. Maslennikova and N. K. Abubakirov, USSR patent no. 191058; Byull. izobr., no. 3, 1967.

16 September 1969

Institute of the Chemistry of Plant Substances, AS UzSSR 